(c) American Dairy Science Association, 2006.

\title{
Factors Affecting Growth Factor Activity in Goat Milk
}

\author{
F. Y. Wu, ${ }^{\star 1}$ P. H. Tsao, ${ }^{\star}$ D. C. Wang, † S. Lin, ${ }^{\star}$ J. S. Wu,† and Y. K. Cheng† \\ ${ }^{*}$ Animal Science Department, National Ilan University, Ilan 26047, Taiwan \\ †Livestock Research Institute, Council of Agriculture, Hueng-Chun 94643, Taiwan
}

\section{ABSTRACT}

Growth factors that are present in goat milk may be responsible for its beneficial effects on the digestive system as described in ancient Chinese medical texts. To develop a nutraceutical product rich in growth factors for promoting gastrointestinal health, it is essential to collect milk with consistently high growth factor activity. Therefore, we investigated the factors affecting growth factor activity in goat milk. Among the 5 breeds of dairy goats tested, milk from Nubian goats had the highest growth factor activity. Tight-junction leakage induced by a 24 -h milking interval did not increase growth factor activity in the milk. Milk collected from pregnant does had a significantly higher growth factor activity than milk collected postpartum. Growth factor activity decreased during the first 8 wk of lactation, fluctuated thereafter, and then increased dramatically after natural mating. During wk 1 to 8 , growth factor activity was inversely correlated with milk yield and week of lactation. No correlation was observed during wk 9 to 29. After natural mating of the goats, the growth factor activity in the milk correlated significantly with somatic cell count and conductivity (a measure of membrane permeability), and correlated inversely with milk yield. Based on the above data, goat milk with higher growth factor activity could be selectively collected from Nubian pregnant does.

Key words: growth factor, goat milk

\section{INTRODUCTION}

Growth factors are useful components of milk, both for the developing offspring and as a potential source for nutraceuticals; however, growth factor activity in milk differs among mammals. Human milk contains physiological levels of growth factors, whereas bovine milk has much lower growth factor activity (Grosvenor et al., 1992; Wu and Elsasser, 1995). Goat milk is another source of physiologically active amounts of growth factors (Wu and Elsasser, 1995). Colostrum from most

Received September 23, 2005.

Accepted December 1, 2005.

${ }^{1}$ Corresponding author: fuywu@niu.edu.tw mammals is rich in growth factors and other bioactive molecules, but the levels of these components decrease rapidly during the first $3 \mathrm{~d}$ of lactation (Brown and Blakeley, 1984; Denhard et al., 2000). Using antibody neutralization assays, Carpenter (1980) first reported that the major growth-promoting activity in human milk is epidermal growth factor (EGF), which was confirmed later by chromatography isolation (Shing and Klagsbrun, 1984). Many other growth factors have been identified in human milk, including IGF-I (Grosvenor et al., 1992), hepatocyte growth factor (HGF; Yamada et al., 1998), and vascular endothelial growth factor (Nishimura et al., 2002).

Growth factors in milk have been implicated in the development of the neonatal gastrointestinal tract (Koldovsky, 1996). For example, EGF helps to establish the epithelial barrier in the gastrointestinal tract (Puccio and Lehy, 1988) and protects the gastroduodenal mucosa by activating ornithine decarboxylase in polyamine synthesis (Konturek et al., 1991). Furthermore, ${ }^{125} \mathrm{I}-\mathrm{EGF}$, when administered orally, can be detected in the blood, lung, and liver of rats and mice (Purushotham et al., 1995; Clarke et al., 2001), demonstrating that growth factors can withstand the harsh condition of gastric acid exposure, and can be absorbed through the gastrointestinal tract to act on other tissues. It has been suggested that milk-derived growth factors may be useful as an orally administered treatment for a wide variety of gastrointestinal disorders (Playford et al., 2000).

Growth factor activity in goat milk, as detected by a cell culture assay, occurs at a much higher level than that in cow milk (Wu and Elsasser, 1995). Thus, goat milk may be a feasible nutraceutical for gastrointestinal disorders. Denhard et al. (2000) reported the presence of EGF in goat milk using a human EGF (hEGF) polyclonal antibody. Prosser et al. (2004) also reported the ability of goat milk to reduce heat-induced gastrointestinal hyperpermeability. These findings support the description in an ancient Chinese medical text of goat milk as a tonic for the digestive system ( $\mathrm{Li}, 1578)$. Preliminary tests of goat milk samples showed high variation in growth factor activity (our unpublished data). To develop a growth factor nutraceutical product, it is necessary to collect milk with a consistently high 
growth factor activity; therefore, we investigated the factors affecting growth factor activity in goat milk.

\section{MATERIALS AND METHODS}

\section{Animals and Milk Sampling}

Milk samples from different breeds were collected from commercial dairy goat farms. The lactation stage and 12- vs. 24-h milking interval experiments were conducted at the Hueng-Chun experimental farm, Livestock Research Institute, Council of Agriculture, Taiwan. Nubian does were machine milked twice daily, except for those in the 24-h milking interval experiment. Milk yield, SCC, and conductivity of the samples were measured. Samples in $2-\mathrm{mL}$ cryotubes were frozen in liquid nitrogen and stored below $-140^{\circ} \mathrm{C}$ until they were used in the growth factor activity assay.

\section{Assay for Growth Factor Activity}

The method of Wu and Elsasser (1995) was slightly modified. In brief, mouse mammary epithelial cells were cultured in 48 -well plates at $20,000 \mathrm{cells} / \mathrm{cm}^{2}$ with Dulbecco's Modified Eagle's Medium/F-12 medium supplemented with transferrin, BSA, antibiotic-antimycotic (Sigma A 4668; Sigma, St. Louis, MO), and 1\% fetal bovine serum (Bios, New Haven, CT). Cells were allowed to grow to confluence, and then the fetal bovine serum was withdrawn from the medium for $4 \mathrm{~d}$ to allow the cells to rest. A milk sample was added to each well and incubated for $18 \mathrm{~h}$. After adding ${ }^{3} \mathrm{H}$-thymidine $(0.5$ $\mu \mathrm{Ci}$; Amersham Biosciences, Buckinghamshire, UK) to each well, the cells were further incubated for $3 \mathrm{~h}$. Cells were fixed with 1:3 acetic acid:methanol, washed with cold 5\% TCA, and lysed with $0.5 \mathrm{M} \mathrm{NaOH} / 0.2 \%$ Triton $\mathrm{X}$-100. The ${ }^{3} \mathrm{H}$-thymidine incorporated into the cells was measured by liquid scintillation counting (TriCarb, Packard, Meriden, CT). The activity of a range of hEGF (R\&D Systems, Minneapolis, MN) concentrations was also measured in each batch to establish a standard curve; 1 unit of activity was defined as the activity equivalent to that of 1 pmol of hEGF.

The mouse mammary epithelial cell line used in this activity assay is known to be activated by EGF or IGF-I (Wu and Elsasser, 1995); therefore, the assay does not distinguish between different types of growth factors. Because EGF is the major growth factor in human milk, we used hEGF as a reference in this assay to define a unit of growth factor activity.

\section{SCC}

Samples were analyzed for SCC using a Fossomatic 5000 basic (Foss Electric, Hillerød, Denmark) according to the manufacturer's instructions. This instrument counts cells based on the presence of DNA, which excludes the large number of vesicles present in goat milk.

\section{Conductivity}

Conductivity was measured with a portable conductivity meter (Eisai Co., Ltd., Tokyo, Japan) calibrated with standard buffer before each use.

\section{Statistical Analyses}

The GLM and Pearson correlation coefficient of the SAS statistical package (SAS Institute, 1988) were used to analyze the data. A Duncan multiple-range test was conducted on the breed effect. The data from the 12and 24-h milking intervals and the pre- and postpartum milkings were analyzed by paired $t$-tests.

\section{RESULTS}

\section{Breed Effect on Growth Factor Activity in Milk}

Growth factor activities in goat milk from 5 different breeds commonly raised in Taiwan are listed in Table 1. Milk from Nubian goats contained the equivalent of $1,085 \pm 270$ units, and was significantly higher $(P<$ 0.01 ) than that of other breeds. Saanen goats usually have higher milk yields than other breeds; however, growth factor activity in Saanen goat milk was not significantly different $(P>0.05)$ from that of Alpine, Toggenburg, or LaMancha goat milk, suggesting that variation in growth factor activity is not merely the effect of dilution by the quantity of milk produced.

\section{Milking Interval Effect on Growth Factor Activity in Milk}

Does were regularly machine milked twice a day, except for those in the 24-h milking interval group. These animals were milked only in the morning on 2 consecutive days, with samples being collected on the first morning as 12-h samples, and on the second morning as 24-h samples. A paired $t$-test analysis for growth factor activity in the 12- and 24-h samples (Figure 1) did not show a significant difference $(P=0.66)$. Stelwagen et al. (1994) reported that tight junctions of mammary epithelial cells begin to disrupt after $21 \mathrm{~h}$ of milk accumulation. This tight-junction leakage may allow growth factors in the serum to diffuse into the milk. However, it appears that once-daily milking is not a feasible way to increase the growth factor activity in goat milk. 
Table 1. Growth factor activity ${ }^{1}$ in goat milk from different breeds

\begin{tabular}{lccccc}
\hline \multicolumn{5}{c}{ Breed } \\
\cline { 2 - 5 } & Nubian & Saanen & Alpine & Toggenburg & LaMancha \\
\hline $\mathrm{n}$ & 10 & 10 & 10 & 9 & 7 \\
$\mathrm{Mean}^{2}$ & 1,085 & 692 & 616 & 590 & 620 \\
$\mathrm{SD}$ & 270 & 96 & 73 & 60 & 80 \\
\hline${ }^{1}$ Units of growth factor activity in milk. & & \\
2The Nubian average was statistically higher $(P<0.01)$ than the other averages. There were no significant \\
differences among any other samples $(P>0.05)$. Mean = Average units of growth factor activity for each \\
breed.
\end{tabular}

\section{Pre- and Postpartum Effects on Growth Factor Activity in Milk}

The growth factor activity of individual Nubian preand postpartum does was highly variable (Table 2 ). A paired $t$-test analysis showed significant differences $(P$ $<0.05$ ) between growth factor activity in the pre- and postpartum milk. Denhard et al. (2000) also reported high levels of EGF and IGF-I in prepartum goat milk. Because gestation results in high levels of estrogen and progesterone in the milk, the high activity in prepartum milk might be due to the presence of steroids instead of growth factors. Therefore, we analyzed whether steroids would have a similar growth factor-like effect in the mouse mammary epithelial cell assay. However, no increase in ${ }^{3} \mathrm{H}$-thymidine incorporation after the addition of either estrogen or progesterone was observed (data not shown), indicating that the high activity in prepartum milk was due to the presence of growth factors.

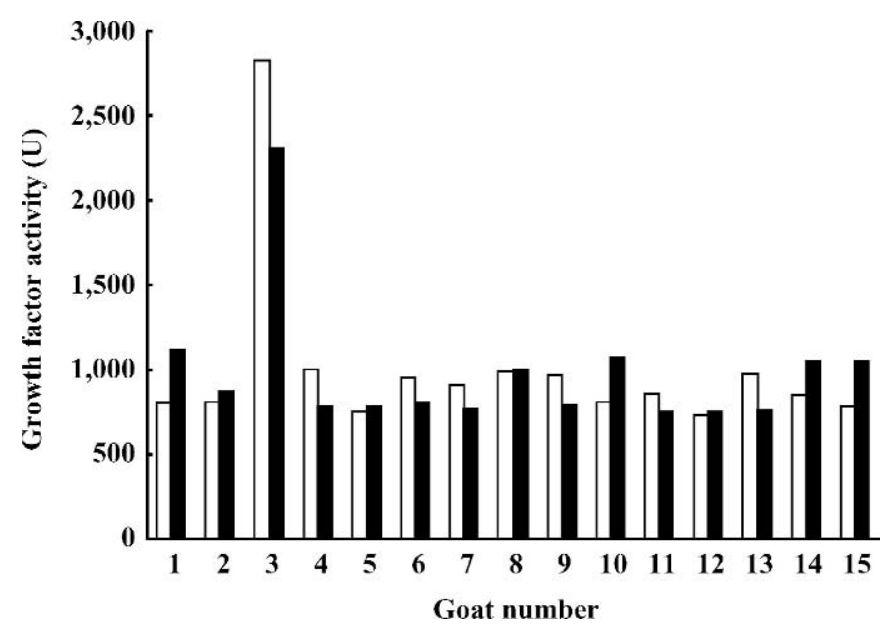

Figure 1. Effect of a 12-h (open bars) or 24-h (solid bars) milking interval on growth factor activity in Nubian goat milk. A paired $t$ test showed no significant difference $(P=0.66)$.

\section{Correlation Analysis of Parameters in Different Stages of Lactation}

Knight and Peaker (1984) reported that milk yield increases in goats during the first 8 wk of lactation and then gradually decreases. Therefore, for correlation analysis, milk sample data were divided into 3 groups: wk 1 to 8 of lactation, wk 9 to 29 (premating), and wk 30 to 37 (postmating). Growth factor activity decreased during the first 8 wk of lactation and fluctuated thereafter until natural mating, whereupon it increased dramatically. During wk 1 through 8, growth factor activity was inversely correlated with milk yield and week of lactation (Table 3). After $8 \mathrm{wk}$ of lactation and before natural mating, no correlation was observed between growth factor activity and the parameters measured. After mating, however, SCC and conductivity (which measures tight-junction leakage) showed very significant $(P<0.001)$ correlations with growth factor activity, whereas milk yield was inversely correlated $(P<0.05)$. Although a high SCC is usually associated with mastitis or poor milk quality in dairy cows, it is normal for goat milk, particularly in the late stages of lactation (Wilson et al., 1995; Zeng and Escobar, 1995).

\section{DISCUSSION}

Many growth factors have been identified in human milk, but little research has been done on growth factors

Table 2. Growth factor activity in goat milk from pre- and postpartum Nubian does

\begin{tabular}{lcc}
\hline Doe number & Prepartum $^{1}$ & Postpartum $^{1}$ \\
\hline 1 & 1,310 & 795 \\
2 & 6,610 & 792 \\
3 & 8,380 & 702 \\
4 & 27,000 & 2,760 \\
Mean $^{2}$ & 13,800 & 1,260 \\
SD & 8,010 & 864 \\
\hline
\end{tabular}

${ }^{1}$ Units of growth factor activity in milk.

${ }^{2}$ Mean $=$ Mean growth factor activity for all 4 does. The means were significantly different at $P<0.05$. 
Table 3. Correlation analysis of growth factor activity with somatic cell count, conductivity, milk yield, and week of lactation ${ }^{1}$

\begin{tabular}{lccccc}
\hline Week of lactation & & SCC & Conductivity & Milk yield & Week \\
\hline 1 to 8 & $\mathrm{r}$ & 0.30 & -0.096 & -0.36 & -0.53 \\
& $P$ & 0.13 & 0.60 & 0.044 & 0.0017 \\
& $\mathrm{n}$ & 27 & 32 & 32 & 32 \\
9 to 29 & $\mathrm{r}$ & 0.032 & 0.092 & -0.090 & -0.10 \\
premating) & $P$ & 0.70 & 0.26 & 0.27 & 0.21 \\
& $\mathrm{n}$ & 144 & 154 & 151 & 154 \\
30 to 37 & $\mathrm{r}$ & 0.55 & 0.74 & -0.41 & 0.050 \\
(postmating) & $P$ & 0.0005 & $<0.0001$ & 0.016 & 0.77 \\
& $\mathrm{n}$ & 36 & 37 & 35 & 37 \\
\hline
\end{tabular}

${ }^{1} \mathrm{r}=$ Pearson correlation coefficient; $P=$ probability; $\mathrm{n}=$ number of samples.

in goat milk. While isolating growth factors in goat milk, we have detected growth factor activity in both fractions that resulted from membrane ultrafiltration with a 50-kDa cutoff (our unpublished data), indicating that more than one type of growth factor is present in goat milk. It is likely that a variety of growth factors are secreted into milk via a variety of routes. Analyzing the growth factors according to their secretory mechanisms may help to identify the factors affecting growth factor activity in milk. Growth factors found in milk may be transferred from blood or secreted from the mammary gland. Tight junctions in mammary alveolar epithelial cells in goats can be induced to leak with 21-h milking intervals (Stelwagen et al., 1994). If the concentration of a growth factor is higher in blood than in milk, it may diffuse into the milk through tightjunction leakage. However, Denhard et al. (2000) reported that the EGF level in serum is lower than that in goat milk. Therefore, EGF is not likely to be introduced into milk by tight-junction leakage. Our data also did not show any increase in growth factor activity of the goat milk taken at 24-h milking intervals.

In the mammary alveolar cells, EGF is synthesized as the membrane-bound prepro-EGF (Brown et al., 1989), whereas milk fat is secreted as a globule surrounded by a cell membrane. Because Nubian goats usually produce milk with more fat content (Sung et al., 1999), EGF may have more opportunities to attach to fat globule membranes in Nubian goats, thereby increasing the amount released into the milk.

Another possible source of growth factor might be migrating neutrophils and macrophages, which constitute the majority of somatic cells in goat milk (Droke et al., 1993). Yamada et al. (1998) detected HGF mRNA expression in the mononuclear cells of human milk and found HGF protein in the cytoplasm of macrophages. Our data show a high correlation $(P<0.001)$ between SCC and growth factor activity in postmating milk, but no correlation was observed before mating, indicating that although somatic cells may be responsible for pro- ducing growth factors in goat milk before mating, gestation may be the major factor that influences the production of growth factors in milk.

Mammary epithelial cells are regulated differently in gestation and lactation. Lactation is the result of differentiation and lactogenesis of the alveolar epithelial cells. The number of mammary cells in lactating goats increases over the first $3 \mathrm{wk}$ of lactation and then starts to decrease after $8 \mathrm{wk}$ (Knight and Peaker, 1984). In contrast, during gestation, mammary cells undergo continuous active proliferation (Neville et al., 2002). Growth factors play important roles as mediators of estrogen and progesterone signaling in mammary development during gestation. Estrogen increases the EGF level, which stimulates expression of the progesterone receptor in mammary epithelial cells (Ankrapp et al., 1998). Neuregulin and HGF are the downstream mediators of progesterone (Yang et al., 1995; Sunil et al., 2002). Epithelial cells also secrete vascular endothelial growth factor to stimulate angiogenesis to supply nutrients (Nishimura et al., 2002). In addition, the tight-junction network of the mammary alveolus becomes highly irregular during gestation (Pitelka et al., 1973), which may facilitate the diffusion of those growth factors into the milk. These may account for the high growth factor activity observed in milk during gestation and the high degree of correlation between growth factor activity and conductivity (membrane permeability) in postmating milk $(P<0.0001)$. The proliferation of mammary epithelial cells is antagonistic to lactogenesis. Jugular vein infusion of EGF in lactating ewes also results in lower milk yield and a reduced concentration of protein in the milk (Gow and Moore, 1992). These findings may be the rationale for the significant inverse correlation between growth factor activity and milk yield before $8 \mathrm{wk}$ or postmating.

\section{CONCLUSIONS}

Nubian does in late-stage lactation with concurrent pregnancy would be a valuable source of milk with high 
growth factor activity. After natural mating, milk with a high growth factor activity could be selectively obtained by collecting milk with a high SCC, high conductivity, or low yield.

\section{ACKNOWLEDGMENT}

This research was funded by the Council of Agriculture in Taiwan.

\section{REFERENCES}

Ankrapp, D. P., J. M. Bennett, and S. Z. Haslam. 1998. Role of epidermal growth factor in the acquisition of ovarian steroid hormone responsiveness in the normal mouse mammary gland. J. Cell. Physiol. 174:251-260.

Brown, C. F., C. T. Teng, B. T. Pentecost, and R. P. DiAugustine. 1989. Epidermal growth factor precursor in mouse lactating mammary gland alveolar cells. Mol. Endocrinol. 3:1077-1083.

Brown, K. D., and D. M. Blakeley. 1984. Partial purification and characterization of a growth factor present in goat's colostrum. Biochem. J. 219:609-617.

Carpenter, G. 1980. Epidermal growth factor is a major growthpromoting agent in human milk. Science 210:198-199.

Clarke, M. Y., J. Brayer, K. Heintz, H. Nagashima, S. Cha, G. E. Oxford, J. M. Nanni, A. B. Peck, T. Zelles, and M. G. HumphreysBeher. 2001. Differential absorption and distribution of epidermal growth factor and insulin-like growth factor in diabetic NOD mice. J. Diabetes Complicat. 15:103-111.

Denhard, M., R. Claus, O. Munz, and U. Weiler. 2000. Course of epidermal growth factor (EGF) and insulin-like growth factor I (IGF-I) in mammary secretions of the goat during end-pregnancy and early lactation. J. Vet. Med. Ser. A 47:533-540.

Droke, E. A., M. J. Paape, and A. L. Di Carlo. 1993. Prevalence of high somatic cell counts in bulk tank goat milk. J. Dairy Sci. 76:1035-1039.

Gow, C. B., and G. P. M. Moore. 1992. Epidermal growth factor alters milk composition and fluid balance of lactating ewes. J. Endocrinol. 132:377-385.

Grosvenor, C. E., M. F. Picciano, and C. R. Baumrucker. 1992. Hormones and growth factors in milk. Endocr. Rev. 14:710-728.

Knight, C. H., and M. Peaker. 1984. Mammary development and regression during lactation in goats in relation to milk secretion. Q. J. Exp. Physiol. 69:331-338.

Koldovsky, O. 1996. The potential physiological significance of milkbone hormonally active substances for the neonate. J. Mammary Gland Biol. Neoplasia 1:317-323.

Konturek, J. W., T. Brzozowski, and S. J. Konturek. 1991. Epidermal growth factor in protection, repair, and healing of gastroduodenal mucosa. J. Clin. Gastroenterol. 13 (Suppl. 1):S88-S97.

Li, S. C. 1578 (Ming dynasty). Pen Tsao Kang Mu (Compendium of Material Medica).

Neville, M. C., T. B. McFadden, and I. Forsyth. 2002. Hormonal regulation of mammary differentiation and milk secretion. J. Mammary Gland Biol. Neoplasia 7:49-66.
Nishimura, S., N. Maeno, K. Matsuo, T. Nakajima, I. Kitajima, H. Saito, and I. Maruyama. 2002. Human lactiferous mammary gland cells produce vascular endothelial growth factor (VEGF) and express the VEGF receptors, Flt-1 and KDR/Flk-1. Cytokine 18:191-198

Pitelka, D. R., S. T. Hamamoto, J. G. Duafala, and M. K. Nemanic. 1973. Cell contacts in the mouse mammary gland. I. Normal gland in postnatal development and the secretory cycle. J. Cell Biol. $56: 797-818$

Playford, R. J., C. E. Macdonald, and W. S. Johnson. 2000. Colostrum and milk-derived peptide growth factors for the treatment of gastrointestinal disorders. Am. J. Clin. Nutr. 72:5-14.

Prosser, C., K. Stelwagen, R. Cummins, P. Guerin, N. Gill, and C. Milne. 2004. Reduction of heat-induced gastrointestinal hyperpermeability in rats by bovine colostrum and goat milk powders. J. Appl. Physiol. 96:650-654.

Puccio, F., and T. Lehy. 1988. Oral administration of epidermal growth factor in suckling rats stimulates cell DNA synthesis in fundic and antral gastric mucosae as well as in intestinal mucosa and pancreas. Regul. Pept. 20:53-64.

Purushotham, K. R., K. Offenmuller, A. T. Bui, T. Zelles, J. Blazsek, G. S. Schultz, and M. G. Humphreys-Beher. 1995. Absorption of epidermal growth factor occurs through the gastrointestinal tract and oral cavity in adult rats. Am. J. Physiol. 269:G867-G873.

SAS Institute. 1988. SAS/STAT User's Guide. SAS Inst. Inc., Cary, NC.

Shing, Y. W., and M. Klagsbrun. 1984. Human and bovine milk contain different sets of growth factors. Endocrinology 115:273-282.

Stelwagen, K., S. R. Davis, V. C. Farr, C. G. Prosser, and R. A. Sherlock. 1994. Mammary epithelial cell tight junction integrity and mammary blood flow during an extended milking interval in goats. J. Dairy Sci. 77:426-432.

Sung, Y. Y., T. I. Wu, and P. H. Wang. 1999. Evaluation of milk quality of Alpine, Nubian, Saanen and Toggenburg breeds in Taiwan. Small Rumin. Res. 33:17-23.

Sunil, N., J. M. Bennett, and S. Z. Haslam. 2002. Hepatocyte growth factor is required for progestin-induced epithelial proliferation and alveolar-like morphogenesis in serum-free culture of normal mammary epithelial cells. Endocrinology 143:2953-2960.

Wilson, D. J., K. N. Stewart, and P. M. Sears. 1995. Effects of stage of lactation, production, parity and season on somatic cell counts in infected and uninfected dairy goats. Small Rumin. Res. 16:165-169.

Wu, F. Y., and T. H. Elsasser. 1995. Studies on cell growth promoting activity in goat milk. J. Chinese Agric. Chem. Society 33:326-332.

Yamada, Y., S. Saito, and H. Morikawa. 1998. Hepatocyte growth factor in human breast milk. Am. J. Reprod. Immunol. 40:112120

Yang, Y., E. Spitzer, D. Meyer, M. Sachs, C. Niemann, G. Hartmann, K. M. Weidner, C. Birchmeier, and W. Birchmeier. 1995. Sequential requirement of hepatocyte growth factor and neuregulin in the morphogenesis and differentiation of the mammary gland. J. Cell Biol. 131:215-226.

Zeng, S. S., and E. N. Escobar. 1995. Effect of parity and milk production on somatic cell count, standard plate count and composition of goat milk. Small Rumin. Res. 17:269-274. 